\title{
Xanthine Oxidase Inhibitory Activities and Crystal Structures of Methoxyflavones from Kaempferia parviflora Rhizome
}

\author{
Kikuyo Nakao, ${ }^{a}$ Kazuya Murata, ${ }^{b}$ Takahiro Deguchi, ${ }^{b}$ Kimihisa Itoh, ${ }^{b}$ Takanori Fujita, ${ }^{c}$ \\ Masayuki Higashino, ${ }^{c}$ Yuri Yoshioka, ${ }^{d}$ Shin-ichi Matsumura,${ }^{d}$ Rika Tanaka, ${ }^{e}$ \\ Tetsuro SHINADA, ${ }^{f}$ Yasufumi OHFune, ${ }^{f}$ and Hideaki Matsuda ${ }^{*, b}$ \\ ${ }^{a}$ Research Institute of Oriental Medicine, Kinki University; 377-2 Ohno-higashi, Osakasayama, Osaka 589-8511, Japan: \\ ${ }^{b}$ Faculty of Pharmacy, Kinki University; 3-4-1 Kowakae, Higashi-osaka, Osaka 577-8502, Japan: ${ }^{c}$ JAPAN TABLET \\ CORPORATION; 149-1 Mekawa, Makishima, Uji, Kyoto 611-0041, Japan: ' Inabata Koryo Co., Ltd.; 3-5-20 Tagawa, \\ Yodogawa, Osaka 532-0027, Japan: ${ }^{e}$ Graduate School of Engineering, Osaka City University; and ${ }^{f}$ Graduate School of \\ Science, Osaka City University; 3-3-138 Sugimoto, Osaka 558-8585, Japan.
}

Received March 17, 2011; accepted March 22, 2011; published online April 12, 2011

Kaempferia parviflora (KP), a Zingiberaceae plant, is used as a folk medicine in Thailand for the treatment of various symptoms, including general pains, colic gastrointestinal disorders, and male impotence. In this study, the inhibitory activities of KP against xanthine oxidase (XOD) were investigated. The extract of KP rhizomes showed more potent inhibitory activity $(38 \%$ at $500 \mu \mathrm{g} / \mathrm{ml})$ than those of the other Zingiberaceae plants tested. Ten methoxyflavones were isolated from the KP extract as the major chemical components and their chemical structures were elucidated by X-ray crystallography. The structurally confirmed methoxyflavones were subjected to the XOD inhibitory test. Among them, 3,5,7,4',5'-pentamethoxyflavone and $3^{\prime}, 4^{\prime}, 5,7$-tetramethoxyflavone showed inhibitory activities $\left(\mathrm{IC}_{50}\right.$ of 0.9 and $>4 \mathrm{~mm}$, respectively) and their modes of inhibition are clarified as competitive/non-competitive mixed type. To the best of our knowledge, this is the first report to present the inhibitory activities of KP, 3,5,7,4',5'-pentamethoxyflavone and $3^{\prime}, 4^{\prime}, 5,7$-tetramethoxyflavone against XOD.

Key words Zingiberaceae; Kaempferia parviflora; rhizome; xanthine oxidase; methoxyflavone; crystal structure

Zingiberaceae, the Ginger family, includes many important medicinal plants and is a rich source of biologically active compounds. In Thailand, a member of the Zingiberaceae family, Kaempferia parviflora (Krachaidum, KP), is used as a folk medicine. The rhizomes and tincture are applied as a medicine for general pains, colic gastrointestinal disorders, and male impotence. In Japan, KP extract is commercially available as an ingredient in supplemental foods for the treatment of metabolic syndrome. Various biological effects of $\mathrm{KP}$, e.g., inhibition of P-glycoprotein function, ${ }^{1)}$ anti-plasmodial, anti-fungal, and anti-mycobacterial effects, ${ }^{2)}$ cytotoxicity against various cancer cell lines, ${ }^{3)}$ anti-cholinesterase activity, ${ }^{4)}$ anti-allergic activity, ${ }^{5)}$ modulation of the function of multidrug resistance associated-proteins, ${ }^{6}$ anti-gastric ulcer effect, ${ }^{7)}$ and anti-obese activity, ${ }^{8)}$ have been demonstrated. From these diverse pharmacological effects, we expected that KP possesses other effects especially related to lifestyle diseases.

Among various lifestyle diseases, we have been performed screening for xanthine oxidase inhibitors (XOD) which expected to improve hyperuricemia. Hyperuricemia can trigger gout and is one of the medical disorders that constitute metabolic syndrome. Control of hyperuricemia is essential in the risk management of gout and related diseases. A straightforward and effective approach is the maintenance of low blood uric acid levels $(<7 \mathrm{mg} / \mathrm{dl})$ using a XOD inhibitor, such as allopurinol, to reduce the biosynthesis of uric acid. However, anti-hyperuricemic agents are known to possess side effects, including impaired kidney function, diarrhea and hepatitis. The development of safe and effective agents for use in clinical treatment has long been anticipated.

In the screening of natural plant or crude drug resources, we found that hydroxychavicol isolated from the Piperaceae plant, Piper betle, is a more potent XOD inhibitor than allo- purinol. ${ }^{9)}$ Recently, the moderate XOD inhibitory activity of mandarin orange, Citrus unshiu, extract has been clarified. ${ }^{10)}$ These reports show that natural plant sources are expected to be promising screening targets for XOD inhibitors.

In this report, we discuss our examination of XOD inhibitors from Zingiberaceae plants. In particular, this study focuses on the extract from the KP rhizome due to its potential pharmaceutical utility. XOD inhibitory effects were compared in the following Zingiberaceae plants: KP, Curcuma longa, Zingiber officinale and C. zedoaria. Among them, the KP extract showed more potent biological activity. Subsequently, in order to clarify the biologically active compounds, the major chemical components of the KP extract were determined. Ten methoxyflavones, which are already known as the active component of $K$. parviflora, were isolated and their chemical structures were determined by X-ray crystallography for the unambiguous elucidation of their chemical structures. These compounds were also assessed using the XOD inhibitory assay to reveal their activities and modes of action.

\section{MATERIALS AND METHODS}

Materials All chemical reagents used in this study were of analytical grade and were purchased from either Wako Pure Chemical (Osaka, Japan), Nacalai Tesque (Kyoto, Japan) or Sigma Aldrich (St. Louis, MO, U.S.A.), unless otherwise stated. KP rhizomes were purchased from Aoba Trading Co. (Tokyo, Japan). C. longa and Z. officinale rhizomes were purchased from Nippon Funmatsu Yakuhin Co., Ltd. (Osaka, Japan). C. zedoaria rhizomes were purchased from Maechu (Nara, Japan). Voucher specimens were deposited at the Faculty of Pharmacy, Kinki University.

Preparations of Extracts Extract was retrieved from KP rhizomes (dried chips, $770 \mathrm{~g}$ ) soaked with 21 of $70 \%$ 
methanol $(\mathrm{MeOH})$ under reflux conditions for $30 \mathrm{~min}$. This extract was filtered (No. 2 filter paper, Advantec, Tokyo, Japan) and the residue was treated with $70 \% \mathrm{MeOH}(21)$ under the same condition described above. The subsequent extract was also filtered (No. 2 filter paper). The combined filtrates were concentrated under reduced pressure. The residue was lyophilized to give the final extract (KP-ext). In a similar manner to the preparation of KP-ext, C. longa $(100 \mathrm{~g}$, dry chip) or Z. officinale ( $100 \mathrm{~g}$, dry chip) was treated twice with $70 \% \mathrm{MeOH}(500 \mathrm{ml})$, followed by the removal of the solvent under reduced pressure to give the corresponding extracts (CL-ext, ZO-ext). Similarly, C. zedoaria (28 g, powder) was treated with $70 \% \mathrm{MeOH}(200 \mathrm{ml})$ under reflux conditions for $2 \mathrm{~h}$ twice, followed by the removal of the solvent under reduced pressure to give the extract (CZ-ext). The yields of KP-ext, CL-ext, ZO-ext and CZ-ext were 13.3\%, $12.3 \%, 7.8 \%$ and $6.3 \%$, respectively.

Assay of Inhibitory Activities against XOD XOD inhibition was evaluated according to previous methods ${ }^{11,12)}$ with minor modifications. Xanthine $(4.27 \mathrm{mg})$ was dissolved in $100 \mathrm{ml}$ of $0.1 \%$ Tween/phosphate buffered saline (PBS) (TwPBS) with gentle heating to make $245 \mu \mathrm{M}$ xanthine buffer. The assay mixture, consisting of $100 \mu$ l of test solution (in dimethylsulfoxide) and $800 \mu \mathrm{l}$ of xanthine buffer, was pre-incubated at $25^{\circ} \mathrm{C}$ for $10 \mathrm{~min}$. The reaction was initiated by the addition of $100 \mu \mathrm{l}$ of enzyme solution $(0.2 \mathrm{units} / \mathrm{ml}$ in TwPBS) and incubated at $25^{\circ} \mathrm{C}$ for $3 \mathrm{~min}$. After adding $100 \mu \mathrm{l}$ of $1 \mathrm{~N} \mathrm{HCl}$ and the assay mixture was filtered using syringe filters (Chromatodisc 4A, GL science, Tokyo, Japan). The filtrate was subjected to HPLC analysis to determine the amount of uric acid produced. HPLC conditions were as follows: column, Develosil RPAQUEOUS (4.6 i.d. $\times 250 \mathrm{~mm}$, Nomura Chemical, Seto, Japan); column temperature, $40{ }^{\circ} \mathrm{C}$; mobile phase, $20 \mathrm{~mm} \mathrm{KH_{2 }} \mathrm{PO}_{4}$; flow rate, $1 \mathrm{ml} / \mathrm{min}$; detection, UV $290 \mathrm{~nm}$; injection volume, $30 \mu \mathrm{l}$. Allopurinol was used as a reference drug. The inhibition (\%) was calculated as follows:

\section{inhibition $(\%)=($ peak area of control - peak area of test solution $) /$ peak area of control $\times 100$}

Purification of Methoxyflavones KP-ext (102.3 g) was dissolved in $500 \mathrm{ml}$ of water and subjected to Diaion HP-20 (Mitsubishi Chemicals, Tokyo, Japan) column chromatography (CC) followed by elution with $\mathrm{H}_{2} \mathrm{O}, 50 \% \mathrm{MeOH}$ and $100 \% \mathrm{MeOH}(500 \mathrm{ml}$ each). The $\mathrm{MeOH}$ fraction was concentrated under reduced pressure. The residue was subjected to silica gel CC ( $n$-hexane : acetone $=7: 3)$. Each fraction was concentrated under reduced pressure to give fractions $\mathrm{A}$ (1.8 g), B (2.3 g), C (3.1 g), and D (4.2 g). After successive fractionation of fractions $\mathrm{A}$ and $\mathrm{B}$ using silica gel $\mathrm{CC}$, ten methoxyflavones including $3^{\prime}, 4^{\prime}, 5,7$-tetramethoxyflavone (1, $0.06 \mathrm{~g}), 3,5,7,3^{\prime}, 4^{\prime}$-pentamethoxyflavone $(2,0.85 \mathrm{~g}), \quad 5,7-$ dimethoxyflavone $(3,0.65 \mathrm{~g}), 4^{\prime}, 5,7$-trimethoxyflavone (4, $0.69 \mathrm{~g}), 3,5,7$-trimethoxyflavone $(\mathbf{5}, 0.75 \mathrm{~g}), 3,5,7,4^{\prime}$-tetramethoxyflavone $(6,1.31 \mathrm{~g}), 5$-hydroxy-3,7,3',4'-tetramethoxyflavone $(7,0.17 \mathrm{~g}), 5$-hydroxy-7-methoxyflavone $(\mathbf{8}, 0.08 \mathrm{~g})$, 5-hydroxy-3,7-dimethoxyflavone $(9,0.69 \mathrm{~g})$, and 5-hydroxy3,7,4'-trimethoxyflavone (10, $0.12 \mathrm{~g})$ were obtained (Fig. 1).

Structural Analysis Methoxyflavone crystals suitable for X-ray crystallography were obtained from re-crystallization from ethyl acetate $/ n$-hexane at room temperature. A

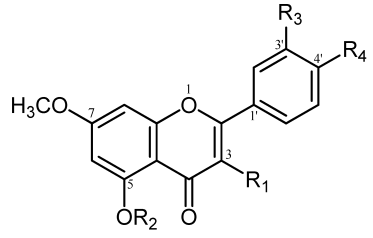

\begin{tabular}{ccccc}
\hline \hline & $\mathrm{R}_{1}$ & $\mathrm{R}_{2}$ & $\mathrm{R}_{3}$ & $\mathrm{R}_{4}$ \\
\hline $\mathbf{1}$ & $\mathrm{H}$ & $\mathrm{CH}_{3}$ & $\mathrm{OCH}_{3}$ & $\mathrm{OCH}_{3}$ \\
$\mathbf{2}$ & $\mathrm{OCH}_{3}$ & $\mathrm{CH}_{3}$ & $\mathrm{OCH}_{3}$ & $\mathrm{OCH}_{3}$ \\
$\mathbf{3}$ & $\mathrm{H}$ & $\mathrm{CH}_{3}$ & $\mathrm{H}$ & $\mathrm{H}$ \\
$\mathbf{4}$ & $\mathrm{H}$ & $\mathrm{CH}_{3}$ & $\mathrm{H}$ & $\mathrm{OCH}_{3}$ \\
$\mathbf{5}$ & $\mathrm{OCH}_{3}$ & $\mathrm{CH}_{3}$ & $\mathrm{H}$ & $\mathrm{H}$ \\
$\mathbf{6}$ & $\mathrm{OCH}_{3}$ & $\mathrm{CH}_{3}$ & $\mathrm{H}$ & $\mathrm{OCH}_{3}$ \\
$\mathbf{7}$ & $\mathrm{OCH}_{3}$ & $\mathrm{H}$ & $\mathrm{OCH}$ & $\mathrm{OCH}_{3}$ \\
$\mathbf{8}$ & $\mathrm{H}$ & $\mathrm{H}$ & $\mathrm{H}$ & $\mathrm{H}$ \\
$\mathbf{9}$ & $\mathrm{OCH}_{3}$ & $\mathrm{H}$ & $\mathrm{H}$ & $\mathrm{H}$ \\
$\mathbf{1 0}$ & $\mathrm{OCH}_{3}$ & $\mathrm{H}$ & $\mathrm{H}$ & $\mathrm{OCH}_{3}$ \\
\hline
\end{tabular}

Fig. 1. Chemical Structures of Methoxyflavones Isolated from KP Rhizomes

crystal was mounted on a glass fiber with epoxy resin. Diffraction data were collected at $200 \mathrm{~K}$ on a RIGAKU AFC/ Mercury Charge Coupled Device (CCD) diffractometer using graphite monochrometer $\mathrm{Mo} K$ radiation $(\lambda=$ $0.71073 \AA$ ). Empirical absorption correction was carried out. The structure was solved by direct methods (SHELXS-97) and refined by the full-matrix least-squares method on all F2 data using the SHELXL-97. Non-hydrogen atoms were refined with anisotropic thermal parameters. Hydrogen atoms, except for those of methyl groups, were found in the difference Fourier maps and refined with isotropic thermal parameters. Hydrogen atoms of methyl groups were placed in geometrically suitable positions where possible and were refined with isotropic thermal parameters riding on those of the parent atoms.

Statistical Analysis Statistical analysis was performed using Statcel2 software (OMS Publishing, Saitama, Japan). Significance differences were detected using a one-way analysis of variance (ANOVA) followed by the Bonferroni/ Dunn multiple comparison test.

\section{RESULTS AND DISCUSSION}

XOD Inhibition of Zingiberaceae Plant Extracts Inhibitory activities of KP-ext, CL-ext, ZO-ext, and CZ-ext against XOD were assessed at 20,50, 200, and $500 \mu \mathrm{g} / \mathrm{ml}$ (Table 1). Among them, KP-ext (38\%) and CL-ext $(25 \%)$ showed potent biological activities at $500 \mu \mathrm{g} / \mathrm{ml}$. In contrast, ZO-ext and CZ-ext did not show any significant activities at the same concentration. Among the extracts of the Zingiberaceae plants tested, KP-ext was the most potent. To the best of our knowledge, this is the first report to clarify the inhibitory activity of KP-ext. The comparative study led us to determine the structure of the biologically active molecules in KPext.

The rhizome of $K$. parviflora has been known as "black turmeric" since its morphological aspects are similar to that of $C$. longa except for its black color. In the view of their differentiation as XOD inhibitor, KP-ext was superior to CL- 
ext. This result indicates that KP-ext is more suitable material as the ingredients of supplemental food designed for anti-hyperuricemic purpose.

Structures of Methoxyflavones Crystal structures have already been reported for all methoxyflavones isolated except for 2, 4 and $7 .{ }^{13-19)}$ The data on the crystal structures has been deposited at CCDC (depository Nos. 801810 - 801819). The structures of naturally occurring methoxyflavones were proposed by the comparison of UV, IR and ${ }^{1} \mathrm{H}$ - and/or ${ }^{13} \mathrm{C}$ NMR spectral data ${ }^{20,21)}$ with those of reported data of the natural product and/or the synthetic molecule without linkage to crystal structures. In this study, we introduced X-ray crystallography because the positions of the methoxyl and hydroxyl group could not be determined by UV, IR and NMR studies (for example 5,7-position vs. 6,8-position) (Fig. 1). In general, the substitution pattern is believed to be the 5,7-positions due to the biosynthetic pathway of the flavones. However, naturally occurring flavonoids, such as baicalein, wogonin and licoflavone, possessing the methoxyl group 5,6,7-, 5,7,8- and 6,7-substitution patterns, were isolated as natural products. As results, the substitutions of the A ring of methoxyflavones $\mathbf{1} \mathbf{- 1 0}$ were clearly determined as the 5 and

Table 1. Inhibitory Activities of KP-ext, CL-ext, ZO-ext and CZ-ext against XOD

\begin{tabular}{cclc}
\hline \hline Samples & Concentration $(\mu \mathrm{g} / \mathrm{ml})$ & Peak area & Inhibition $(\%)$ \\
\hline Control & - & $201107 \pm 4514$ & - \\
KP-ext & 20 & $181829 \pm 1605^{*}$ & 10 \\
& 50 & $172042 \pm 1299^{* *}$ & 14 \\
& 200 & $147841 \pm 2188^{* *}$ & 26 \\
CL-ext & 500 & $123914 \pm 1799^{* *}$ & 38 \\
& 20 & $189810 \pm 2454$ & 6 \\
& 50 & $187262 \pm 2359$ & 7 \\
& 200 & $172091 \pm 1960^{* *}$ & 14 \\
ZO-ext & 500 & $150879 \pm 594 * *$ & 25 \\
& 20 & $189924 \pm 4168$ & 6 \\
& 50 & $189912 \pm 361$ & 6 \\
& 200 & $189502 \pm 2884$ & 6 \\
CZ-ext & 500 & $190791 \pm 6831$ & 5 \\
& 20 & $183477 \pm 2428$ & 9 \\
& 50 & $186538 \pm 284$ & 7 \\
& 200 & $188974 \pm 2601$ & 6 \\
\hline \multirow{2}{*}{ Allopurinol } & 500 & $187997 \pm 3986$ & 7 \\
& $10 \mu \mathrm{M}$ & $112574 \pm 2441^{* *}$ & 44
\end{tabular}

Each value represents the mean \pm S.E. of triplicates. Significantly different from control value, $* p<0.05, * * p<0.01$.

\section{7 positions}

XOD Inhibitory Activities of Methoxyflavones The inhibitory activities of isolated methoxyflavones were investigated Among the compounds tested, $\mathbf{1}$ and $\mathbf{2}$ showed potent inhibitory activities (36\% and $52 \%$ at $400 \mu \mathrm{M}$, respectively) as shown in Table 2 (ORTEP figures are shown in Fig. 2). Their $\mathrm{IC}_{50}$ values were $>4 \mathrm{~mm}$ (1) and $0.9 \mathrm{~mm}$ (2) from the experiments at $0.01,0.1,0.5,1,2$ and $4 \mathrm{~mm}$ of dose for 1 and $0.01,0.1,0.5,1$ and $2 \mathrm{~mm}$ of dose for $2 . \mathrm{IC}_{50}$ values seem to be higher than the estimation from the data shown in Table 2 since their activity reached peak over $0.5 \mathrm{~mm}$ of concentration.

Table 2. Inhibitory Activities of Methoxyflavones Obtained from KP-ext against XOD

\begin{tabular}{|c|c|c|c|}
\hline Samples & Concentration $(\mu \mathrm{M})$ & Peak area & Inhibition (\%) \\
\hline Control & - & $212523 \pm 4150$ & - \\
\hline \multirow[t]{3}{*}{1} & 100 & $153044 \pm 3512 * *$ & 28 \\
\hline & 200 & $144078 \pm 3773 * *$ & 32 \\
\hline & 400 & $136644 \pm 2654 * *$ & 36 \\
\hline \multirow[t]{3}{*}{2} & 100 & $140961 \pm 2514 * *$ & 34 \\
\hline & 200 & $122251 \pm 2915^{* *}$ & 43 \\
\hline & 400 & $102045 \pm 991 * *$ & 52 \\
\hline \multirow[t]{3}{*}{3} & 100 & $194507 \pm 3501 * *$ & 9 \\
\hline & 200 & $191053 \pm 144 * *$ & 10 \\
\hline & 400 & $187420 \pm 1831 * *$ & 12 \\
\hline \multirow[t]{3}{*}{4} & 100 & $188678 \pm 2384 * *$ & 11 \\
\hline & 200 & $185951 \pm 3385^{* *}$ & 13 \\
\hline & 400 & $188857 \pm 324 * *$ & 11 \\
\hline \multirow[t]{3}{*}{5} & 100 & $198223 \pm 1932 *$ & 7 \\
\hline & 200 & $196215 \pm 2572 * *$ & 8 \\
\hline & 400 & $189787 \pm 1970 * *$ & 11 \\
\hline \multirow[t]{3}{*}{6} & 100 & $192665 \pm 702 * *$ & 9 \\
\hline & 200 & $189087 \pm 342 * *$ & 11 \\
\hline & 400 & $191936 \pm 1633 * *$ & 10 \\
\hline \multirow[t]{3}{*}{7} & 100 & $192249 \pm 649 * *$ & 10 \\
\hline & 200 & $190690 \pm 2341 * *$ & 10 \\
\hline & 400 & $194385 \pm 2175^{* *}$ & 9 \\
\hline \multirow[t]{3}{*}{8} & 100 & $185176 \pm 765^{* *}$ & 13 \\
\hline & 200 & $189235 \pm 1714^{* *}$ & 11 \\
\hline & 400 & $191105 \pm 1516^{* *}$ & 10 \\
\hline \multirow[t]{3}{*}{9} & 100 & $189854 \pm 1756^{* *}$ & 11 \\
\hline & 200 & $199231 \pm 927$ & 6 \\
\hline & 400 & $198545 \pm 1893^{*}$ & 7 \\
\hline \multirow[t]{3}{*}{10} & 100 & $196491 \pm 404^{* *}$ & 8 \\
\hline & 200 & $200052 \pm 756$ & 6 \\
\hline & 400 & $194929 \pm 1945^{* *}$ & 8 \\
\hline Allopurinol & 10 & $132708 \pm 2658^{* *}$ & 38 \\
\hline
\end{tabular}

Each value represents the mean \pm S.E. of triplicates. Significantly different from control value, $* p<0.05, * * p<0.01$.
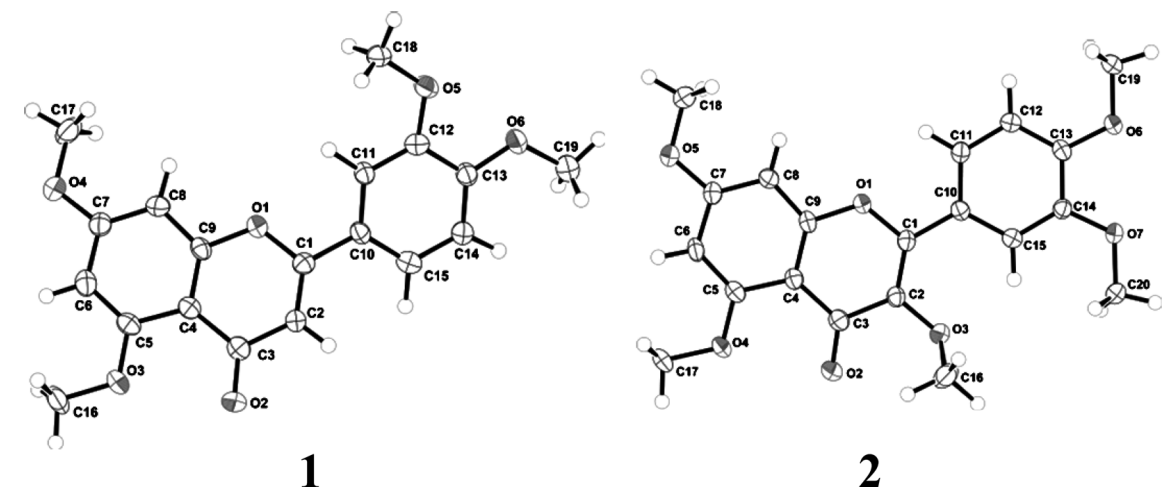

Fig. 2. ORTEP Figures of Methoxyflavones $\mathbf{1}$ and $\mathbf{2}$ Isolated from KP Rhizomes 
From these results, active principles were clarified as $\mathbf{1}$ and 2 and the preliminary structure-activity relationship of methoxyflavones can be assumed as follows. From comparison of the activities of $\mathbf{2}$ and 7, replacement of the methoxyl group to a hydroxyl group at position 5 reduced the activity. From comparison of the activities of $\mathbf{2}$ and $\mathbf{6}$, the methoxyl group at position $3^{\prime}$ is needed to express the activity. However, 7, which possess a methoxyl group at position $3^{\prime}$, did not show significant inhibitory activity. The decrease in potency of 7 may due to the hydroxyl group in position 5 .

Methoxyflavones are known as multi-potent compounds possessing aldose reductase $\mathrm{e}^{22)}$ and nitric oxide inhibitory activities, ${ }^{23)}$ estrogenic activity, ${ }^{24)}$ cancer chemopreventive activity, ${ }^{25)}$ inhibitory activities against protein glycation, ${ }^{26)}$ multidrug resistance protein $1^{27)}$ and degranulation from rat mast cells. ${ }^{28)}$ Although the inhibitory activity of acacetin, 5,7-hydroxy-4'-methoxyflavone (mono-methoxyflavone), against XOD has already been reported, ${ }^{29)}$ this is the first report to show the XOD inhibitory activities of methoxyflavones $\mathbf{1}$ and 2.

In conclusion, this study clarified the following points: 1) for the first time, the inhibitory activity of KP-ext was demonstrated, 2) the structures of methoxyflavones were determined using X-ray crystallography, 3) inhibitory activities of methoxyflavones were determined and it was revealed that $\mathbf{1}$ and $\mathbf{2}$ were the principle active components of the XOD inhibitory activity of KP-ext. These results show that KP-ext holds promise as an anti-hyperuricemic agent for use as a food supplement. Further in vivo study on the anti-hyperuricemic activity of KP-ext and $\mathbf{2}$ is now underway in our laboratory.

Acknowledgement This study was financially supported by the "Antiaging Center Project" for Private Universities from the Ministry of Education, Culture, Sports, Science and Technology of Japan, 2008-2012.

\section{REFERENCES}

1) Patanasethanont D., Nagai J., Yumoto R., Murakami T., Sutthanut K., Sripanidkulchai B. O., Yenjai C., Takano M., J. Pharm. Sci., 96, 223233 (2007).

2) Yenjai C., Prasanphen K., Daodee S., Wongpanich V., Kittakoop P., Fitoterapia, 75, 89-92 (2004).

3) Yenjai C., Wanich S., Bioorg. Med. Chem. Lett., 20, 2821-2823 (2010).
4) Sawasdee P., Sabphon C., Sitthiwongwanit D., Kokpol U., Phytother. Res., 23, 1792-1794 (2009).

5) Tewtrakul S., Subhadhirasakul S., Kummee S., J. Ethnopharmacol., 116, 191-193 (2008).

6) Patanasethanont D., Nagai J., Matsuura C., Fukui K., Sutthanut K., Sripanidkulchai B. O., Yumoto R., Takano M., Eur. J. Pharmacol., 566, 67-74 (2007)

7) Rujjanawate C., Kanjanapothi D., Amornlerdpison D., Pojanagaroon S., J. Ethnopharmacol., 102, 120-122 (2005).

8) Akase T., Shimada T., Terabayashi S., Ikeya Y., Sanada H., Aburada M., J. Nat. Med., 65, 73-80 (2011).

9) Murata K., Nakao K., Hirata N., Namba K., Nomi T., Kitamura Y., Moriyama K., Shintani T., Iinuma M., Matsuda H., J. Nat. Med., 63, $355-359$ (2009).

10) Nakao K., Murata K., Itoh K., Hanamoto Y., Masuda M., Moriyama K., Shintani T., Matsuda H., J. Trad. Med., 28, 10-15 (2011).

11) Chang W. S., Lee Y. J., Lu F. J., Chiang H. C., Anticancer Res., 13, 2165-2170 (1993).

12) Nagao A., Seki M., Kobayashi H., Biosci. Biotechnol. Biochem., 63 1787-1790 (1999)

13) Aree T., Sawasdee P., Acta Crystallogr., 65, 2706 (2009).

14) Fun H. K., Razak I. A., Boonnak N., Laphookhieo S., Chantrapromma S., Acta Crystallogr., 61, 3086-3088 (2005).

15) Nallasivam A., Nethaji M., Vembu N., Ragunathan V., Sulchana N., Acta Crystallogr., 65, 504-505 (2009).

16) Sharma D., Gupta V. K., Brahmachari G., Mondal S., Gangopadhyay A., Bull. Mater. Sci., 30, 469-475 (2007).

17) Shoja M., Z. Kristallogr., 212, 385-386 (1997).

18) Shoja M., Acta Crystallogr., 45, 828-829 (1989).

19) Teh J. B. J., Fun H. K., Razak I. A., Boonnak N., Chantrapromma S., Karalai C., Acta Crystallogr., 61, 3653-3655 (2005).

20) Sutthanut K., Sripanidkulchai B., Yenjai C., Jay M., J. Chromatogr. A, 1143, 227-233 (2007).

21) Azuma T., Tanaka Y., Kikuzaki H., Phytochemistry, 69, 2743-2748 (2008).

22) Mastuda H., Morikawa T., Toguchida I., Yoshikawa M., Chem. Pharm. Bull., 50, 788-795 (2002).

23) Matsuda H., Morikawa T., Ando S., Toguchida I., Yoshikawa M., Bioorg. Med. Chem., 11, 1995-2000 (2003).

24) Choi S. Y., Ha T. Y., Ahn J. Y., Kim S. R., Kang K. S., Hwang I. K., Kim S., Planta Med., 74, 25-32 (2008).

25) Walle T., Ta N., Kawamori T., Wen X., Tsuji P. A., Walle U. K., Biochem. Pharmacol., 73, 1288-1296 (2007).

26) Matsuda H., Wang T., Managi H., Yoshikawa M., Bioorg. Med. Chem., 11, 5317-5323 (2003).

27) van Zanden J. J., Wortelboer H. M., Bijlsma S., Punt A., Usta M., Bladeren P. J., Rietjens I. M. C. M., Cnubben N. H. P., Biochem. Pharmacol., 69, 699-708 (2005).

28) Matsuda H., Morikawa T., Ueda K., Managi H., Yoshikawa M., Bioorg. Med. Chem., 10, 3123-3128 (2002).

29) Nguyen M. T. T., Awale S., Tezuka Y., Shi L., Zaidi S. F. H., Ueda J. Y., Tran Q. L., Murakami Y., Matsumoto K., Kadota S., Biol. Pharm. Bull., 28, 2231-2234 (2005). 